\title{
NILAI BUDAYA PADA ANTOLOGI PUISI JUKUNG WAKTU KARYA ABDURRAHMAN EL HUSAINI
}

\author{
Hidayati Desy \\ Akademi Maritim Nusantara Banjarmasin \\ Hidayati_desy@ymail.com
}

\begin{abstract}
Abstrak
Bahasa sebagai media, kata sastra atau kesustraan dapat ditemui dalam sejumlah pemakaian yang berbeda-beda. Hal ini menggambarkan bahwa sastra bukanlah nama dari sesuatu yang sederhana, tetapi merupakan "Payung" yang meliputi sejumlah kegiatan yang berbeda. Selain bisa dihubungkan dengan suatu kegiatan penyimakan, pembacaan naskah, majalah atau buku, sastra juga berkaitan dengan sebuah budaya, salah satunya adalah budaya Banjar. Terdapat beberapa karya yang dimiliki oleh salah satu sastrawan Banjar yaitu Abdurrahman El Husaini. Penelitian ini bertujuan untuk Mendeskripsikan wujud nilai budaya pada antologi puisi Jukung Waktu karya Abdurrahman El Husaini serta Memaparkan fungsi nilai budaya pada antologi puisi Jukung Waktu karya Abdurrahman El Husaini, yang mengandung nilai budaya dan cerita budaya Banjar. Nilai budaya dapat digunakan sebagai media ditiap daerah untuk menyampaikan nilai kepercayaan, gagasan, sensasi, atau perasaan dengan cara seefektif mungkin untuk objek tersebut. Budaya dan senipun menjadi kesatuan yang tak terpisahkan karena akan menjadi simbol dari tiap kekhasan nilai budaya khsususnya budaya Banjar. Pendekatan yang digunakan dalam penelitian ini adalah pendekatan antropologi sastra dengan menggunakan analisis data dokumentasi. Adapun hasil penelitian ini memiliki keragaman bukan hanya dari tutur kata, agama yang saling hormat menghormati, melainkan juga tutur bahasa dan kebiasaan dari budaya Banjar yang menjadi ciri khas masyarakat Banjar, misalnya masyarakat Banjar dikenal sebagai pribadi yang santun, lemah lembut, serta saling peduli dengan orang lain. Dengan demikian dapat disimpulkan bahwa budaya merupakan pendekatan yang menekankan pada sebuah makna terhadap seni tradisional yang dapat dilihat melalui tulisan dan lisan dalam suatu karya sastra, khususnya yang ada di daerah dengan tujuan memperkenalkan karya sastra dalam dokumentasi buku yang ditulisnya tersebut.
\end{abstract}

Kata kunci : Nilai, Budaya, Puisi Jukung Waktu

\begin{abstract}
Abstrack
Language as a medium. The word literature or literature can be found in a number of different uses. This illustrates that literature is not the name of something simple, but it is a term "Umbrella" which includes a number of different activities, it can be connected with a listening activity or reading magazine or book manuscripts, literature is also related to a culture, one of them is a Banjar culture in which there are several works owned by one of the Banjar writers, namely Abdurrahman El Husaini, which aims to describe the manifestation of cultural values in Abdurrahman El Husaini's anthology of Jukung Waktu poetry and to describe the function of cultural values in Abdurrahman El's anthology of Jukung poetry. Husaini, which contains cultural values and stories of Banjar culture, cultural values can be used as a medium in each region to convey the values of beliefs, ideas, sensations, or feelings in the most effective way possible for these objects. Culture and art have become an inseparable unity because they will
\end{abstract}


become symbols of each specific cultural value, especially Banjar culture. The approach used in this research is the literary anthropological approach. By using documentary data analysis, the results of this study have diversity not only in terms of speech, religions that respect each other, but also the spoken language and customs of the Banjar culture which are characteristic of the Banjar people, for example the Banjar people are known as polite, weak individuals. gentle, and care for each other. The approach used in this study is the anthropological approach to literature. With the conclusion that culture is an approach that emphasizes a meaning to traditional art that can be seen through written and spoken language in a literary work, especially literature in the area in order to introduce and enrich a literary literature in the documentation of the book he wrote.

Keywords: Values, Budsya, Poetry of Jukung Wakttu

\section{PENDAHULUAN}

Pada hakikatnya sastra sebuah hasil karya yang diciptakan baik dalam bentuk lisan maupun tulisan. Istilah sastra paling tepat diterapkan pada seni sastra yaitu sastra sebagai karya imajinatif, sedangkan sastra imajinatif yang memiliki tulisan indah dan berisikan sebuah makna-makna yang mendalam sesuai judul yang dituliskan pada lariklarik puisi, yang mana tertuliskan dengan indah dan sopan. Selain itu pula karya sastra khususnya pada puisi memiliki struktur yang dapat dikembangkan seperti menurut Suslisyowati dan Effendi, (2013: 2) yang mengungkapkan sebuah puisi merupakan stuktur makna, pengaruh nilai budaya dalam sebuah karya sastra sangatlah penting hal ini bertujuan pada kemajuan kebudayaan untuk generasi berikutnya. Dengan demikian, nilai budaya leluhur yang menjadi adat istiadat serta kebiasaan yang merupakan salah satu ciri utama pada setiap kegiatan merupakan seni yang dimiliki budaya Banjar tersebut, belum lagi adanya wisata yang banyak menarik perhatian dan mampu membuat pengunjung betah. Begitu pula dengan kaitan sastra pada budaya Banjar. Salah satunya adalah madihin, baturai pantun, dan kegiatan seni budaya Banjar pada umumnya baik dipentaskan ataupun dilisankan merupakan pengaruh besar karena bertujuan memperindah keelokan budaya Banjar itu sendiri.

Wujud nilai budaya umumnya sangat identik dengan sebuah nilai-nilai yang menjadi sebuah kebiasaan, kepercayaan, ciri khas serta simbol dari kebudayaan itu sendiri. Sifat kebudayaan dapat dilihat secara nyata dan dirasakan oleh masyarakat Indonesia. Seperti yang diungkapkan oleh Koentjaraningrat, (2000:76) suatu wujud kebudayaan dapat dibagi menjadi empat macam sebagai berikut.

Pertama, sistem budaya. Kebudayaan mempunyai sifat abstrak yang hanya dapat diketahui dan dipahami berdasarkan suatu sistem tertentu. Berdasarkan sistem budaya daerah dengan perbedaan suku dan bahasa menjadi pemahaman diluar akal manusia. Jika memang nyata benar adanya bahwa sistem budaya dahulu masih melekat contohnya saja pada budaya Banjar ialah batapung tawar. Batapung tawar dimaksud adalah menawarkan doa-doa yang dibacakan untuk orang yang sakit karena adanya jin atau makhluk halus pada diri seseorang, dengan demikian batapung tawar pun menjadi tradisi masyarakat Banjar untuk membersihkan diri dari makhluk gaib lainnya agar bersih kembali.

Kedua, kebudayaan fisik. Merupakan wujud paling besar dan paling konkret. Contohnya bangunan-bangunan megah layaknya bangunan Candi Borobudur ataupun benda bergerak lainnya seperti kapal tanker, dan lain sebagainya. Kebudayaan fisik 
pada budaya Banjar dapat dilihat secara garis besar seperti pada patung bakantan menjadi moment yang tidak akan dilewatkan saat berwisata ke Banjar, bakantan adalah simbol dari hewan Kalimantan yang mana hidung tersebut panjang walaupun sama jenisnya dengan warik.

Ketiga, sistem sosial. Sistem sosial adalah pola tingkah laku manusia yang akan memberikan gambaran tentang wujud suatu tingkah laku seseorang berdasar pada suatu sistem. Sistem sosial sebagai kebudayaan yang bersifat konkret yang dapat didokumentasikan dan diabadikan. Sistem sosial pada budaya Banjarpun seperti pada kehidupan masyarakat pada umumnya adalah saruan, yaitu pakaian formal seperti batik, sarung, jilbab, peci serta perhiasan di tangan serta perhiasan merias wajah saar berkunjung ke undangan tersebut.

Keempat, nilai budaya. Nilai kebudayaan merupakan gagasan yang banyak dipelajari warga sejak dini dan sulit untuk dirubah. Gagasan ini nantinya akan menghasilkan berbagai macam benda yang diciptakan manusia. Sistem nilai budaya sangat kuat meresap dalam jiwa warga masyarakatnya, sehingga sukar diganti dengan nilai-nilai budaya lain dalam waktu singkat. Menurut, Hanafie (2016:33) pada ahli antopologi Khuckhohn, membagi sistem nilai budaya ke dalam lima masalah: (1) Hakekat hidup manusia; (2) Hakekat karya manusia; (3) Hakekat kedudukan manusia dalam ruang dan waktu; (4) Hakekat hubuingan manusia dengan alam; (5) Hakekat hubungan manusia dengan sesamanya.

Nilai budaya pada budaya banjar contohnya adalah pembuatan kambang barenteng serta kue jalabia sebagai ciri khas dari budaya banjar yang dapat dikembangkan melalui gagasan terbaru yang mampu menjadi contoh di kebudayaan banjar tersendiri. Penggolongan nilai budaya salah satunya terdapat pada nilai kebenaran. Dalam sebuah cerita selain memiliki kebenaran terdapat pula nilai keindahan dan kebaikan. Sebuah cerita tentu memiliki unsur keindahan. Nilai religious tidak akan selalu hadir pada setiap cerita. Keberagaman nilai yang ada dalam budaya atau kultur manusia, berdasarkan arah tujuan dan fungsi nilai bagi kehidupan manusia dapat digolongkan menjadi tiga jenis menurut (Sukatman 1992:15), yaitu sebagai berikut.

Pertama, Nilai hidup ketuhanan manusia, nilai hidup ketuhanan manusia seperti halnya religius, sehingga segala sesuatu hidupnya bernaung dan yakin hanya kepada Allah swt, serta bertakwa dan menjalankan semua perintah ketuhanan, seperti sholat, puasa, berdoa, zakat, haji dan lain sebagainya. Kedua, Nilai sosial kehidupan manusia, adalah sebuah interaksi yang terjalin sabagaimana mestinya. Masyarakat memerlukan bantuan orang lain sebagai makhluk yang saling membutuhkan. Dengan demikian, kehidupan manusia sangat diperlukan karena dapat membangun interaksi kebudayaan yang lebih bermartabat serta saling menghormati dan gotong royong. Nilai sosial tersebut tidak jauh dari contoh budaya Banjar seperti halnya pada acara saruan, serta rumah lanting yang menjadi sarana sastra untuk mengembangkan peningkatan kebudayaan banjar menjadi lebih baik. Ketiga, Nilai kehidupan pribadi manusia adalah lebih kepada individu atau manusia itu sendiri. Hal tersebut sesuai dengan tingkah laku baik maupun buruk pribadi manusia itu sendiri, karena manusia tidak terlepas dari kekurangan dan kesalahan.

\section{METODE}

Metode yang digunakan dalam penelitian ini adalah metode deskriptif kualitatif. Penggunaan metode ini adalah memecahkan masalah dengan cara mengumpulkan 
data, menyusun data, mengklasifikasikan data, menganalisis data, menginterprestasikan data serta hasil penelitian secara apa adanya sesuai dengan data yang diperoleh dalam penelitian Ratna, (2012:53) menyatakan bahwa analisis deksriptif yang berarti memberikan arti tambahan, tidak semata-mata menguraikan melainkan juga memberikan secara rinci dari mendapatkan arti, makna serta pemahaman dan penjelasan secukupnya.Teknik pengumpulan data pada penelitian ini memiliki beberapa tahapan yang harus dilakukan sesuai bahan dokumentasi yang dikumpulkan, sehingga teknik pengumpulan data pada penelitian ini adalah sesuai dengan cara, kejadian teknik ditentukan adanya alat yang dipakai literatur lain yang relevan yang memiliki proses beberapa tahapan.

Tahapan yang dilakukan pada teknik pengumpulan data sebagai berikut. Tahap pertama, mempersiapkan literatur-literatur yang berhubungan dengan apa yang akan diteliti. Sehingga dalam pelaksanaan penelitian tidak mengalami kendala yang berarti. kemudian pada tahap berikutnya menentikan apa yang akan diteliti. Tahap kedua, Tahap Pelaksanaan Pada tahap ini peneliti mengumpulkan bahan dan mengamati bahan tersebut, dan peneliti menyesuaikan dengan apa yang akan ditulis atau diteliti. Teknik analisis data yang digunakan dalam penelitian ini adalah teknik analisis nilai budaya dan karya sastra yang dibahas menggunakan sistem analisis dokumentasi dan pemaknaan yang lebih mendalam. Endaswara, (2008:67) menyatakan bahwa analisis antropologi sastra dapat mengikuti tahap-tahap tertentu khususnya analisis puisi, yaitu: Penguntaian dan pengorganisasian data, yaitu menuju pada proses pengurutan puisi sesuai pemilihan data.

\section{HASIL DAN PEMBAHASAN}

Kebudayaan merupakan ekspesi, ungkapan kehadiran manusia, karena manusia tidak terlepas dari nilai leluhur kebudayaan dari ciri khas masing-masing daerah. Hal itu dikarenakan kebudayaan adalah suatu alat yang digunakan dan berlaku dalam masyarakat. Dengan demikian, kebudayaan ada karena ada manusia penciptamya dan manusia dapat hidup di tengah kebudayaan yang diciptakannya. Kebudayaan akan terus hidup manakala ada manusia sebagai pendukungnya. Terciptanya atau terwujudnya suatu kebudayaan adalah sebagai hasil interaksi antara manusia dengan segala isi alam raya ini. Wujud Nilai umumnya sangat identik dengan sebuah nilai-nilai yang menjadi sebuah kebiasaan dan kepercayaan yang menjadi ciri khas serta simbol dari kebudayaan itu sendiri, yang mana sifat kebudayaan dapat dilihat secara nyata dan dirasakan khususnya masyarakat Indonesia.

\section{Sistem Budaya}

Kebudayaan mempunyai sifat abstrak yang hanya dapat diketahui dan juga dipahami dimana wujud kebudayaan ini mempunyai pola tertentu berdasarkan suatu sistem tertentu. Hal tersebut termasuk pada daerah Banjar yang memiliki sistem kebudayaan yang hanya dipahami oleh orang terterntu saja sebagai salah satu sistem yang disepakati tersebut.

Berdasarkan hasil analisis data, peneliti menemukan wujud nilai budaya pada puisi Banjar karya Abdurrahman El Husaini. Adapun beberapa puisi Jukung Waktu yang mengandung sistem budaya, yaitu Kambang Barenteng, Bapidara, Balarangan, Batapung Tawar, Rumah Lanting, dan Panawar Kalumpanan yang total keseluhan adalah 9 buah pembahasan. Di bawah ini akan diuraikan nilai sistem budaya yang terkandung dalam antologi puisi Jukung Waktu adalah sebagai berikut. 
[1] Kakambangan bamacam macam rupa Kuputik kurentengrenteng jadi serenteng Kususun jadi sasusun Di hijir gadang nang sigar Nyaman ditating Nyaman diliat Harum dicium [KB : B3]

Pada kutipan [1] sistem budaya pada judul Kambang barenteng dapat dilihat secara abstrak namun hanya pada sistem tertentu yang dapat memahaminya seperti pada Bait 3 larik 1 - 8 yaitu : Kambang Barenteng / Kakambangan bamacam-macam rupa / Kuputik kurentengrenteng jadi serenteng/ Kususun jadi sasusun/ Di hijir gadang nang sigarl Nyaman ditating/ Nyaman diliat / Harum dicium sistem budaya yang terdapat pada larik satu hingga delapan sebagai sistem kebudayaan dari daerah Banjar dan sekitarnya, karena ikambang barenteng pada umumnya sering digunakan dalam rangka acara-acara yang sangat sakral untuk orang banyak seperti acara sunatan, pernikahan, perkawinan, pengajian, mandi-mandi pengantin dan tujuh bulanan serta acara lainnya. Dengan demikan, kambang barenteng sebagai salah satu yang wajib ada pada acaraacara dan pada intinya acara kambang barenteng tersebut memiliki makna yang mana setiap model dari kambang memiliki makna tersendiri. Kambang barenteng memiliki beberapa macam warna dan rupa, serta model hinggga dipakai sampai dijadikan sebagai hiasan pada acara ataupun digantung sebagai salah satu hiasan-hiasan acara lainnya. kambang barenteng tersebut sebagai salah satu sistem budaya Banjar pada umumnya..

[2] Bakasai raja salawat wan doa panawar dingin

Bapupur janar wan kapur

Di dahi

Di pipi

Di awak

Di tangan

Di batis

Sagala datunya panyakit wan munyangnya urang halus Huuuuuuuuuuuus! Lakasi bajauh [BP : B1]

Pada kutipan [2] sebagai sistem budaya di atas tersebut adalah budaya Banjar yang dapat dilihat secara abstrak namun hanya pada sistem tertentu yang dapat memahaminya seperti pada bait 1 larik 1-9 yaitu Bapidara / Bakasai raja salawat wan doa panawar dingin /Bapupur janar wan kapur / Di dahi / Di pipi / Di awak /Di tangan IDi batis/ Sagala datunya panyakit wan munyangnya urang halus/ Huиииииииииus! Lakasi bajauh /Allahummasolliaalasyaidinamuhammad waalaalihisyaidinamuhammad pada larik yang dituliskan di atas merupakan salah satu sistem budaya Bapidara . Bapidara adalah sejenis penyakit yang tidak dapat dideteksi oleh dokter namun memiliki obat dengan salah satu bapidara. Pada budaya Banjar, Bapidara hanya bisa dilakukan oleh orang-orang tertentu saja karena ada beberapa bacaan dan keturunan yang diwariskan pada beberapa orang yang mampu membuang penyakit di diri seseorang tersebut. 
[3] Bakasai raja salawat wan doa panawar dingin $\quad$ [BP : B1]

Pada kutipan [3] penjelasan pada bait 1 larik 1 sebagai kebudayaan masyarakat Banjar, seperti Bakasai raja salawat wan doa panawar dingin saat bapidara itu pun seseorang harus nenerima seluruh wajah dan badan diolesi oleh kunyit yang diberi juga dengan kapur basah tidak lepas dengan doa yang dapat membuang penyakit tersebut, seperti shalawat dan doa penawar lainnya.

[4] Sahasta pantangan

Nang diharumi di kukus dupa

Daham hampai basusut di situ

$[\mathrm{BL}: \mathrm{B} 2]$

Pada kutipan [4] di atas tersebut pun juga terdapat sistem budaya yang dapat dilihat secara abstrak namun hanya pada sistem tertentu yang dapat memahaminya pada puisi Balarangan terdapat pada bait 2 larik 5-7 yaitu Sahasta pantangan/ Nang diharumi di kukus dupa/ daham hampai basusut di situ sistem budaya pada kedua larik tersebut adalah salah satu kebudayaan Banjar karena berupa pantangan dan keharusan tradisi dalam pelaksanaan kukus dupa tersebut.

Dengan demikian, pada sistem budaya Balarangan adalah pantangan yang tidak boleh dilanggar oleh siapapun yang mempercayai tersebut, agar mampu berbaik hati kepada siapa pun dan dijadikan contoh yang harus jujur sesuai dengan tingkah laku, jika tidak maka pantang untuk mengambil seorang menjadi istri. Hal tersebut ada pada budaya Banjar sebagai acuan dalam kepribadian diri wanita yang masih perawan sehingga harus menjaga dengan baik tingkah laku dan moral budaya Banjar, karena balarangan yang sudah berikat tali cinta menjadi pantangan untuk keluar rumah dan lingkungan.

\author{
[5] Batapung tawar \\ Tawar tawar \\ Manyingkai \\ Umbayang hirang \\ Suntup sabakasan \\ Tasisa \\ Carunung \\ Mahawar kadap
}

$$
[\mathrm{BT}: \mathrm{B} 1]
$$

Pada kutipan [5] puisi di atas terdapat sebuah sistem budaya pada judul Bapatung Tawar dapat dilihat secara abstrak namun hanya pada sistem tertentu yang dapat memahaminya. Terdapat pada bait 1 larik 1-8 yaitu Batapung tawarl Tawar tawarl Manyingkail Umbayang hirang/ Suntup sabakasan/ Tasisal Carunung/ Mahawar kadap sistem budaya yang dapat dilihat sesuai pemahaman orang tertentu saja di jelaskan pada larik di atas bahwa batapung tawar membuat seseorang lebih terbuka dan bercahaya lagi dalam artian membasmi sesuatu yang jahat yang ada di diri sehingga membuka kembali lembaran baru sebelum betapung tawar tersebut ada sedikit keganjilan pada diri seorang tersebut.

Sistem budaya Banjar pada umumnya sering melakukan Batapung tawar saat ada acara yang harus diberikan kepada setiap pengunjung agar memiliki makna lebih 
baik pada kehidupan. Batapung tawar juga memiliki bacaan-bacaan serta doa yang menapung tawari masyarakat Banjar.

\section{[6] rumah lanting $\quad[R L]$}

Pada kutipan [6] di atas tersebut, sebagai sistem budaya pada judul Rumah Lanting dapat dilihat secara abstrak namun hanya pada sistem tertentu yang dapat memahaminya seperti bait 5 larik 4 yaitu Gasan disalukut api camburu kata-kata pada larik tersebut menjadi salah satu sistem budaya yang terlihat abstrak namun dapat dipahami oleh beberapa yang mengenal dari kalimat tersebut, seperti disembunyikan dengan api cemburu melalui kata-kata bisa menjadi ujung tombak pertengakaran yang dapat membuat amarah saat berkumpulnya rumah lanting dengan ujian berbeda-beda, dengan demikian untuk menutupi kecemburuan pada larik di atas diperlukan seorang yang dapat memahami sebuah sastra di dalamnya.

\section{[7] Larut dihanyutakan baah kata-kata [RL : B6]}

Pada kutipan [7] larik tersebut terdapat pada bait 6 larik 4 juga terdapat sistem budaya, salah satunya adalah Larut dihanyutakan baah kata-kata. Larik tersebut adalah pemahaman yang dirasakan dan pemaknaan pada bagian para sastra yang berkumpul di rumah lanting tersebut, dengan dihanyutkan beberapa kata-kata yang hambarpun menjadi seorang yang mampu memahami kalimat tersebut dengan kata-kata lainnya sehingga tidak baah atau keruh dalam sebuah permasalahan.

[8] Kalumpanan lurung bulik

Daun hati dihulun

Lunguy di guncang kumarau landang [PK : B1]

Pada kutipan [8] larik yang tertuliskan di atas tersebut, terdapat sistem budaya pada judul Panawar Kalumpanan dapat dilihat secara abstrak. Namun hanya pada sistem tertentu yang dapat memahaminya terdapat pada bait 1 larik 1-3 yaitu Kalumpanan lurung bulik / Daun hati dihulun / Lunguy di guncang kumarau landang pada larik di atas tersebut menjadi sistem budaya yang abtrak namun dapat dipahami oleh orang tertentu saja. Salah satunya kalumpanan yang berarti kelilipan yang mana saat terkena sebuah kelilipan di mata tersebut merasakan keanehan dihati seseorang yang mengalami kalumpanan atau kelilipan. Dengan demikian, selagi masih terkedala tersebut maka bagaikan kemarau yang menerpa diri seseorang. Dengan demikan tidak dapat dilihat secara wujud nyata hanya yang merasakan dalam dirilah menjadi perpaduan raga yang aneh dan harus segera diselesaikan.

[9] Kalumpanan lurung bulik

Daun hati dihulun

Lunguy di guncang kumarau landang $\quad$ [PK : B1]

Pada kutipan [9] larik yang tertuliskan tersebut, terdapat pada bait 1 larik 17 juga terdapat hal abtrak tersebut seperti Manawar kalumpanan. Larik panawar kalumpanan adalah sebuah obat yang akan dilakukan oleh ahlinya. Hal tersebut karena tak kasat mata dilakukan secara medis, kalumpanan yang didasari oleh orang halus tersebut 
menjadi penyakit dari yang mengalami saat berada di luar rumah. Dengan demikian, manawar kelumpanan dapat melihat apa saja penyebab penyakit. Hal tersebut dapat diobati melalui sebuah doa yang diberikan segelas air untuk diminum dan beberapa waktupun kalumpanan tersebut akan hilang.

\section{Kebudayaan Fisik}

Kebudayaan fisik merupakan wujud paling besar dan paling konkret. Contohnya, kebudayaan fisik pada budaya Banjar dapat dilihat secara garis besar seperti halnya pada patung bakantan menjadi moment yang tidak akan dilewatkan saat berwisata ke Banjar, bekantan adalah simbol dari hewan Kalimantan yang mana hidung tersebut panjang walaupun sama jenisnya dengan warik. Berdasarkan hasil analisis data, peneliti menemukan wujud nilai budaya pada puisi Banjar karya Abdurrahman El Husaini yaitu beberapa puisi Jukung Waktu yang mengandung kebudayaan fisik, yaitu Jalabia, Kambang barenteng, Saruan, dan Rumah lanting, yang total keseluruhan adalah 7 buah pembahasan. Di bawah ini akan diuraikan nilai sistem budaya yang terkandung dalam antologi puisi Jukung Waktu adalah.

\section{[10] Jalabia $\quad[\mathrm{JB}]$}

Pada kutipan [10] di atas tersebut, budaya pada kebudayaan fisik atau yang nyata dilihat dan diabadikan sebagai salah satu ciri khas dari budaya Banjar tersendiri terdapat pada judul kata Jalabia, yang mana jalabia adalah sebuah kue khas Banjar sebagai satu kesatuan untuk mempererat silaturahmi kebersamaan saat berkumpul dan santai. Jalabia inipun sangat mudah untuk dibuat karena tidak terlalu ribet dan hanya digorang saja.

\section{[11] Kambang Barenteng \\ Kakambangan bamacammacam rupa \\ Kuputik kurentengrenteng jadi serenteng \\ Kususun jadi sasusun \\ Di hijir gadang nang sigar $\quad[\mathrm{KB}: \mathrm{B} 1]$}

Pada kutipan [11] yang mengandung kebudayaan fisik atau budaya secara nyata dilihat terletak pada sebuah judul Kambang Barenteng seperti pada bait 1 larik 1-5 yaitu Kambang Barenteng / Kakambangan bamacammacam rupa / Kuputik kurentengrenteng jadi serenteng / Kususun jadi sasusun / Di hijir gadang nang sigar pada bait pertama dibeberapa larik di atas tersebut sebagai salah satu kebudayaan fisik yang dapat dilihat karena secara nyata kambang barenteng tersebut memiliki makna pada budaya Banjar tersebut. Beberapa jenis kembang yang digunakan pun memiliki wujud yang dipercaya sebagai salah satu hakikat kebaikan jika sesuai dengan tujuan. Sistem sosial adalah pola tingkah laku manusia dimana sistem ini akan memberikan gambaran tentang wujud suatu tingkah laku dari seorang manusia. Sistem sosial sebagai kebudayaan tentunya bersifat konkret dan dapat didokumentasikan dan diabadikan, seperti pada halnya sikap pribadi seseorang dalam bersosial dan bergotong royong pada suasana adat tertentu.

Berdasarkan hasil analisis data, peneliti menemukan wujud nilai budaya pada puisi Jalabia karya Abdurrahman El Husaini yaitu beberapa puisi Jukung Waktu yang mengandung sistem sosial, yaitu Jalabia, Kambang Barenteng, Bapidara, Banyu Mata Doa, Balarangan, Saruan, Jukung Waktu, Habar Banua, Rumah lanting, Jukung Waktu 
dan Panawar Kalumpanan sehingga total keseluruhan adalah 25 pembahasan. Di bawah ini akan diuraikan nilai sistem budaya yang terkandung dalam antologi puisi Jukung Waktu adalah:

$$
\text { [17] Kubangkit kusurungi panas panas [JB : B1] }
$$

Pada kutipan [17] di atas, sistem sosial lebih kepada tingkah laku dan sifat dari khas budaya dan seorang manusia berdasarkan sistem. Yang menjadi konkret atau dapat dicontohkan, didokumentasikan dan diabadikan seperti pada bait 1 larik 10 yaitu Kubangkit kusurungi panas panas yang mana pada puisi tersebut menjadi salah satu sifat dari budaya Banjar yang lebih mengutamakan keakraban dan berkumpulnya satu keluarga untuk menikmati sebuah jalabia tersebut.

\section{[18] Mancium bau awak kuitan $\quad$ [ZH : B1]}

Pada kutipan [18] yang terdapat sistem sosial pada judul Ziarah lebih kepada tingkah laku dan sifat dari khas budaya dan seorang manusia berdasarkan secara sistem. Dapat dicontohkan, didokumentasikan dan diabadikan seperti pada bait 1 larik 1 yaitu Mancium bau awak kuitan sebagai bentuk dari sosial budaya Banjar yang hormat dan patuh kepada kedua orangtua yang telah melahirkan kita. Pada larik mancium bau awak kuitan yang diartikan sebagai mencium aroma orang tua yang telah meninggal. Pada puisi tersebut masing mengingat dan mengenang jasa dari seorang ibu dan bukti sistem sosial yang taat khsusunya pada budaya Banjar itu sendiri.

$$
\begin{aligned}
& \text { [19] Kaganangan juakah ingui tangis sidin nang maharagu } \\
& \text { maranakakan? } \\
& \text { Wayah siang malam diniari baisukan }[\mathrm{ZH}: \mathrm{B} 1] \quad \ldots
\end{aligned}
$$

\section{Nilai Budaya}

Nilai kebudayaan merupakan gagasan yang banyak dipelajari warga sejak dini dan sulit untuk dirubah. Gagasan ini nantinya akan menghasilkan berbagai macam benda yang diciptakan manusia ataupun dapat dijadikan sebagai contoh untuk tahap berikutnya sebagai perkembangan dari nilai budaya. Berdasarkan hasil analisis data, peneliti menemukan wujud nilai budaya pada puisi Jalabia karya Abdurrahman El Husaini yaitu beberapa puisi Jukung Waktu yang mengandung nilai budaya, yaitu Jalabia, Kambang barenteng, Bapidara, Balarangan, Batapung tawar, Saruan, Habar banua, dan Rumah lanting sehingga total yang ditemukan adalah 14 buah pembahasan. Di bawah ini akan diuraikan nilai sistem budaya yang terkandung dalam antologi puisi Jukung Waktu adalah sebagai berikut. Nilai budaya Banjar yang dapat memperkaya gagasan yang banyak dipelajari warga sejak diri untuk dirubah, gagasan ini nantinya akan menghasilkan berbagai macam benda yang diciptakan manusia. Seperti pada bait 1 larik 5-12 yaitu :

[42] Bawara kahada bawara

Kusambitsambit

Paputingan hahimpilan tatakan

Kupulun mambulat mambulaning

Bapupur lawan galapung baras 
Tutukkan babinian bujang nang baluman datang rigat

Di lasung ulahan aruan nini datu

Limbah kutimang timang

Kusanga kubulak balik

Kubangkit kusurungi panas panas

Wayah liur manyurung

Bakawan kupi wan bakawan ruku

Talah sasangaan

Kuripingnya gin nyaman

Kuripingnya gin langis [JB : B1]

Pada kutipan [42] di atas terdapat pada bait 1 dibeberapa larik dari judul Jalabia tersebut menjadi salah satu nilai budaya Banjar yang memiliki gagasan pada masyarakat luar pada umumnya. Membuat jalabia sebagai salah satu kue khas Banjar yang dibuat dengan nyaman dan mudah seperti halnya Paputingan hahimpilan tatakan / Kupulun mambulat mambulaning /Bapupur lawan galapung baras. Sebuah jalabia yang terbuat dari tepung beras dan diadon hingga merata sampai dapat digulung sesuka hati kemudian digoreng di wajan yang sudah disiapkan minyak goreng panas. Dengan demikian, pada gagasan budaya Banjar dapat diterapkan di rumah saat berkumpul dengan keluarga besar untuk tujuan menghangatkan suasana di rumah dengan lebih baik.

\section{Nilai Kehidupan Pribadi Manusia}

Nilai kehidupan pribadi manusia adalah lebih kepada individu atau diri manusia itu sendiri. Hal tersebut dapat dikatakan sesuai dengan tingkah laku baik maupun buruk merupakan nilai kehidupan pribadi manusia itu sendiri, karena manusia tidak terlepas dari kekurangan dan kesalahan. Berdasarkan hasil analisis data, peneliti menemukan fungsi nilai budaya pada puisi Jalabia karya Abdurrahman El Husaini yaitu beberapa puisi Jukung Waktu yang mengandung nilai kehidupan pribadi manusia, yaitu Jalabia, Ziarah, Kambang Barenteng, Banyu Mata Doa, Balarangan, Saruan, Habar Banua, Lumah lanting, Jukung Waktu dan Kanawar kalumpanan. Total keseluruhan adalah 22 buah pembahasan. Di bawah ini akan diuraikan nilai sistem budaya yang terkandung dalam antologi puisi Jukung Waktu adalah sebagai berikut.

[85] Bawara kahada bawara

Kusambitsambit

Paputingan hahimpilan tatakan

Kupulun mambulat mambulaning

Bapupur lawan galapung baras

[JB : B1]

Pada kutipan [85] di atas, sifat yang dimiliki oleh manusia terletak pada saat aktifitas yang dilakukan oleh salah satu larik menjadi nilai kehidupan pribadi manusia. Seperti pada bait 1 larik 1-5 yaitu Bawara kahada bawara/Kusambitsambit /Paputingan hahimpilan tatakan/ Kupulun mambulat mambulaning/ Bapupur lawan galapung baras. Kehidupan seorang pembuat jalabia yang dilakukannya dengan sendiri. Awal pembuatan yang mulai memotong potongan kecil pisang hingga adonan tepung beras, dan akhirnya menggiling adonan dengan tangan hingga digoreng sampai disajikan 
dengan keluarga di rumah. Salah satu bentuk dari nilai kepribadian manusia yang sangat mandiri dengan kerajinan yang dibuat pada tokoh di larik jalabia tersebut.

[86] Kusanga kubulakbalik

Kubangkit kusurungi panas panas

Wayah liur manyurung

Bakawan kupi wan bakawan ruku

Talah sasangaan $\quad[\mathrm{JB}: \mathrm{B} 1]$

Pada kutipan [86] yang terdapat satu bait di atas telah ditemukan kehidupan pribadi manusia pada bait 1 larik 9-13 Kusanga kubulakbalik/ Kubangkit kusurungi panaspanas/ Wayah liur manyurung/ Bakawan kupi wan bakawan rukul Talah sasangaan. Larik tersebut menjadi salah satu nilai kehidupan pribadi karena pada budaya Banjar. Masyarakat Banjar sangat hormat kepada sesama keluarga dan lainnya. Dengan demikian, salah satu aktivitas setelah menggoreng dan membolak-balikkan jalabia agar matang dengan sempurna tersebut telah habis tak tersisa oleh keluarga yang menyantap dan menikmatinya. Hal tersebut juga termasuk membuat dengan hati ikhlas dan rasa sayang pada keluarga. Hal inilah menjadi salah satu budaya masyarakat Banjar dari dulu hingga sekarang.

\section{PENUTUP}

Sistem kebudayaan Banjar berdasarkan sistem budaya daerah dengan perbedaan suku dan bahasa menjadi pemahaman di luar akal manusia. Jika memang nyata benar adanya, bahwa sistem budaya dahulu masih melekat. Contohnya saja pada budaya Banjar ialah batapung tawar. Batapung tawar adalah menawarkan doa-doa yang dibacakan untuk orang yang sakit karena adanya jin atau makhluk halus pada diri seseorang. Kebudayaan fisik pada budaya Banjar dapat dilihat secara garis besar seperti pada patung bakantan menjadi moment yang tidak akan dilewatkan saat berwisata ke Banjar. Bakantan adalah simbol dari hewan Kalimantan yang hidungnya panjang. Walaupun sama jenisnya dengan warik dan yang lain. Nilai budaya pada budaya Banjar contohnya adalah pembuatan kambang barenteng serta kue jalabia sebagai ciri khas dari budaya Banjar yang dapat dikembangkan melalui gagasan terbaru yang mampu menjadi contoh di kebudayaan Banjar tersendiri. Nilai hidup ketuhanan manusia tersebut sarat dengan Tuhan seperti halnya religius. Hidupnya bernaung dan yakin hanya kepada Allah Swt serta bertakwa dan menjalankan semua perintah ketuhanan, seperti sholat, puasa, berdoa, zakat, haji dan lain sebagainya. Nilai sosial kehidupan manusia, adalah sebuah interaksi yang terjalin sesame manusia. Masyarakat memerlukan bantuan orang lain. Dengan demikian, kehidupan manusia sangat diperlukan karena dapat membangun interaksi kebudayaan yang lebih bermartabat serta saling mengormati dan gotongroyong. Nilai sosial tersebut tidak jauh dari contoh budaya Banjar seperti halnya pada acara saruan, serta rumah lanting yang menjadi sarana sastra untuk mengembangkan peningkatan kebudayaan Banjar lebih baik. Nilai kehidupan pribadi manusia adalah lebih kepada individu atau diri kepribadian manusia itu sendiri. Hal tersebut dapat dikatakan sesuai dengan tingkah laku baik maupun buruk merupakan nilai kehidupan pribadi manusia itu sendiri, karena manusia tidak terlepas dari kekurangan dan kesalahan. 


\section{DAFTAR PUSTAKA}

El Husaini, Abdurrahman. 2012. Jukung Waktu. Banjarbaru: Scripta Cendekia.

Endraswara, Suwardi. 2008 Metodologi Penelitian Sastra (Epistemologi, Model, Teori, dan Aplikasi). Yogyakarta: Center for Academic Publishing Service ( CAPS ).

Hanafie,Sri Rahayu Djatimurti Rita.2016. Ilmu Sosial Buadaya Dasar.Yogyakarta. CV Andi Offset

Koentjaraningrat. 2000. Pengantar Ilmu Antropologi. Jakarta: Rineka Cipta.

Ratna, Nyoman Kutha. 2012. Penelitian Sastra. Yogjakarta: Pustaka Pelajar. 